\title{
La subversión que reproduce al sistema opresor. Un análisis del personaje "El Jaguar" en la novela La ciudad y los perros.
}

\author{
The subversion that reproduces the oppressing system. An \\ analysis of the character "El Jaguar" in the novel La ciudad y los \\ perros.
}

Esta obra está bajo una Licencia Creative Commons Atribución 4.0 Internacional. DOI: $10.32870 /$ sincronia.axxii.n74.19b18

\author{
Gilbert Ulloa Brenes \\ Universidad Estatal a Distancia \\ (COSTA RICA) \\ gilbertodalier@gmail.com
}

Recibido: $29 / 01 / 2018$

Revisado: $02 / 02 / 2018$

Aprobado: $19 / 03 / 2018$

\section{RESUMEN}

La novela La ciudad y los perros de Mario Vargas Llosa ha sido objeto de diversos estudios analíticos que enfatizan el tema de la violencia como un elemento central en la argumentación de la obra. Este ensayo retoma esa línea analítica pero ofrece una discusión centrada en el comportamiento subversivo de "el Jaguar" y el aparentemente contradictorio desenlace de la novela, cuando ese personaje aparece plenamente adaptado a la sociedad. Por ello, se propone un concepto de subversión que sin descartar la resistencia o el intento por contravenir un determinado orden institucional, permite reconocer la posible armonización respecto de la lógica dominante a la que se opone y de la cual sería una versión sub, que en última instancia coadyuva con la óptima funcionalidad del sistema.

Palabras clave: Literatura latinoamericana. Novela. Sociedad. Violencia. Subversión.

\section{ABSTRACT}

Mario Vargas Llosa's novel La ciudad y los perros has been subject of varied analytical studies that focus on the theme of violence as a central element in the argumentation of the piece. This essay 
applies that analytical approach but offers a discussion centered on the subversive behavior of "el Jaguar", and on the seemingly contradictory ending of the novel when the character has fully adapted to society. This analysis proposes a concept of subversion that, without discarding the resistance or the attempt to stand against the institutional frame, allows the recognition of the possible harmonization with the dominant logic to which it is opposing and of which a sub version emerges. This sub version ultimately contributes to the optimal functionality of the system.

Keywords: Latin American Literature. Novel. Society. Violence. Subversion.

\section{Introducción}

Según la convencional referencia al diccionario de la Real Academia de la Lengua Española, subvertir es "Trastornar, revolver, destruir, especialmente en lo moral" (RAE, 2001, párr. 1). Así, comúnmente se asocia la subversión a una actividad que propende al trastorno de la situación que la motiva. Es el caso del uso del término asociado a manifestaciones sociales, cuando se comprenden bajo el apelativo de subversivos a grupos que tratan de contraponerse, derruir o trastornar determinado orden imperante.

Por ejemplo, en términos de acción política la subversión implicaría, según apunta Carrasco (2012), un movimiento que desde abajo y hacia arriba propende a dar vuelta por completo a una situación estructural de las relaciones sociales desde su propia base, provocando una "inversión de lo que ya estaba invertido y que se lo hacía ver como al derecho" (p. 10).

En ese sentido, la subversión deviene epistemológicamente en una crítica a un sistema de relaciones que en realidad estaría al revés. Y cuando esta crítica se traslada al ámbito artístico permite la elaboración de una crítica estético-epistemológica que

[...] no tiene que estar referida a objetos estéticos, sino más bien a la forma de mirar el objeto de conocimiento y mostrarlo en ángulos imposibles de mirada, que es la forma de desafiar la mirada tradicional, acostumbrada, habitual, ingenuamente realista (¿burguesa?), y que por ello ya nos entrega una representación diferente del objeto, pero donde dicha diferencia y ángulo de mirada lo pone en entredicho (Carrasco, 2012, p. 13). 
Según lo anterior, la subversión sería más bien una vuelta sobre el orden correcto de la realidad, el cual había sido alterado ideológicamente por un grupo social que quería presentar como válida su organización del mundo.

Esa perspectiva puede llevar incluso a otras posiciones críticas desde las cuales se plantea la subversión como alteración crítica de un orden que, ideológicamente, sojuzga y obnubila al presentar como válida solamente una cierta realidad en detrimento de otras visiones y experiencias.

Sin embargo, desde el punto de vista que sustenta este ensayo, se propone que también, desde otro punto de vista, la subversión lejos de amenazar seriamente la estabilidad de una estructura social puede entenderse como una versión sub que apuntala desde un subnivel la lógica estructural dominante.

De acuerdo con una metáfora tomada en préstamo de la Informática, el concepto de subversión aquí planteado, entonces, semeja más al del software llamado Subversion, el cual es un sistema de control de versiones encargado de coordinar los cambios que diferentes usuarios de un sistema informático puedan hacer en archivos de trabajo compartidos y dispuestos en un reservorio común, lo cual garantiza que las modificaciones hechas se armonizarán para todos los usuarios manteniendo así el sistema con la óptima funcionalidad (Collins-Sussman, Fitzpatrick \& Pilato, 2004).

En ese sentido, al igual que el software homónimo, en el análisis que se presenta aquí se toma como punto de partida que la subversión antes que ser una revuelta radical de la lógica dominante de un sistema social, también puede derivar en su continuidad metaforizada a través de versiones sub que logran apuntalar la lógica dominante, bajo las especies de otro discurso o de otros comportamientos que, sin embargo, tienden a armonizar con la visión de fondo a la que se oponen.

Esta forma de concebir la subversión ha sido motivo de análisis en otro trabajo (Ulloa, 2007) enfocado en la dimensión religiosa del Rastafarismo, cuyo universo simbólico propende a la ruptura 
del esquema de mandato-sumisión sustentado en una realidad social profana (Jamaica bajo el Imperio Británico, es decir, la vida en Babylon), subvirtiendo ese esquema básico en una versión sagrada proyectada en el anhelado reino de Etiopía (el imperio de Haile Selassie sobre África unida), en la cual la relación mandato-sumisión es plenamente aceptada como una relación hipostática.

En el ámbito literario es posible hallar un buen ejemplo de este tipo de subversión en el personaje "el Jaguar", dentro de la novela La ciudad y los perros de Mario Vargas Llosa, por lo cual el objetivo de este artículo consiste en proponer a modo de hipótesis que las acciones del personaje "el Jaguar" corresponden precisamente a una subversión dentro del colegio militar Leoncio Prado que, no obstante, apuntala el sistema dominante pergeñado por el autor como escenario institucional.

Para alcanzar este propósito se analizan parte de las acciones que sostiene "el Jaguar" dentro de la institución con base en la metodología del Análisis de Personajes, Atributos y Acciones Relativas (Ulloa, 2006), entendiendo que, desde este punto de vista, el personaje como tal es un rol determinado por los atributos que se le asignan y las acciones relativas que este mantiene ante los otros personajes, dentro de la estructura del texto como realidad narrada.

El Análisis de Personajes, Atributos y Acciones Relativas se sustenta en la construcción de modelos analíticos que permitan explicar partes significativas de un texto a partir de tres grandes categorías heurísticas:

a) los personajes, cada uno de los sujetos mencionados explícitamente en el discurso por medio de sustantivos personales; b) los atributos anotados como frases o rasgos marcados por sustantivos o adjetivos que hablan de las características de un mismo personaje; y c) las acciones relativas, es decir, las frases que marcan determinadas formas de acción entre personajes que interactúan en el discurso (Ulloa, 2006, p. 41).

Si bien se trabaja el tema de la subversión como apuntalamiento del sistema desde una perspectiva inherente, mirando cómo esta se da dentro de la estructura de la novela estudiada, ello permitirá 
establecer algunas ideas relativas a la subversión como fenómeno cultural dentro de la realidad social.

Esto implica discutir respecto de la dimensión sociocultural de la subversión y cómo ella expresada dentro de textos literarios supondría una especie de homología con respecto al todo social.

Por otra parte, esta perspectiva se ofrece como una exégesis alternativa a otros estudios que ya han indagado sobre aspectos sociales que se pueden rastrear en la obra La ciudad y los perros, por ejemplo, la violencia como tema central de la novela entendiendo que las relaciones dadas en el texto son sub-productos de esquemas relacionales prototípicos de la realidad peruana del momento (Salazar, 2005), o cómo esas interacciones violentas entre los personajes son expresión de ciertas pautas de identidad masculina propios de América Latina (Martínez-Hoyos, 2015), incluyendo la detección de elementos urbanísticos culturalmente característicos de la ciudad de Lima presentes en la novela (Medina, 2012) en donde la violencia tiende a ser una constante. También, el estudio efectuado por Demouche (2016), si bien abarca un análisis más general de la obra, llama la atención sobre la manera como "el Jaguar" hace uso de la violencia como medio para combatir la injusticia que impera en el Colegio Militar Leoncio Prado.

En efecto, el ejercicio de la violencia (quién puede ejercerla y para qué) es un elemento que se entiende como clave dentro de los diferentes análisis hechos a la trama de La ciudad y los perros, repercutiendo incluso, tal como apunta Montes (2011), en la carga semántica de la metáfora "perro" como zoomorfismo en el que se ubica a varios de los personajes sometidos, pues "el miedo se articula a la violencia y, a través de lo que rodea a la palabra perro, a la dualidad: dominación / esclavitud" (p. 70).

\section{Dimensión sociocultural de la subversión}

Para el análisis de la subversión como aspecto sociocultural es oportuno trabar discusión a partir de la dimensión lingüística y de la ontológico-cultural. 
En primer lugar, desde un punto de vista lingüístico, para Pérez (2001) la subversión implicaría una forma del lenguaje que consigue ir más allá del discurso puramente referencial, adquiriendo los matices de un discurso poético, por lo que deviene inminentemente simbólico y de fuerte carácter ideológico. Para este autor se debe

[...] pensar en la subversión como en la desviación de las fuerzas habituales de los lenguajes [...]. Se trata de ver aquí las posibilidades que tiene el lenguaje para transgredir su propia naturaleza comunicadora, para hacer de la comunicación y de su ausencia en el silencio, ideología. Manejo interesado de las ideas, la ideología funciona como perturbación de los equilibrios y de las linealidades de la consciencia. Como un río subterráneo -profundo-, está la subversión, siempre ideológica, entrando en juego para condicionar las lecturas del lenguaje y para imprimirle una carga de valor muy alto, tanto a lo que dice como a lo que calla, al cómo dice lo que dice y al porqué no dice lo que silencia (p. 130).

Pérez (2001) acierta en reconocer el carácter simbólico, altamente metafórico, de la subversión. Sin embargo, no es que se trate de un discurso sin anclaje referencial, pues lo subversivo es, más bien, una metáfora fuertemente vinculada a un sistema social que funciona como gran marco referencial. Solo ahí, dentro de ese marco es posible el surgimiento de la subversión como versión subterránea de un discurso dominante, es decir, como versión que se mueve bajo las superficies de una superversión que le da sentido.

El aspecto metafórico de una subversión guardaría relación, entonces, con la posibilidad de prolongar la lógica dominante de un sistema bajo las apariencias de un discurso o un comportamiento pretendidamente contrario, enarbolado por grupos alternativos.

En términos socioculturales, esto supone que la subversión traduce a otros lenguajes lo que en la sociedad, como referente, es la explícita dominancia lógica. Así, la subversión consigue presentar una versión subterránea de lo social dominante sin transgredirlo, sino, por el contrario, 
apuntalándolo en otros órdenes simbólicos donde se plantea una ilusoria idea de transgresión que permite armonizar el sistema social.

Esto conlleva discrepar con Negri (2006) para quien la revolución, como posibilidad para la potencia de un nuevo sujeto, pasaba por una especie de revolución ética y estética derivada de una política de la transformación

El ser es, el no ser no es: así reza la antigua sentencia. Sin embargo, este ser que se ha tornado en absoluta contingencia, es posibilidad de nuevo ser. La constitución subjetiva filtra la posibilidad de constitución ontológica y enraiza esta última en la estética trascendental. La analítica nos ha restituido el mundo como absoluta contingencia: con ello se funda la radical posibilidad de la innovación alternativa (pp. 201-202).

Como puede verse, Negri maneja una idea de lo subversivo en asocio con la de una revolución de matices ontológicos y dentro de una línea similar, quizá con consecuencias más radicales, Rosas (2004) plantea implícitamente una idea de subversión que, además de asociarse a la transformación, se condensa con las ideas de la rebeldía y la resistencia social.

Efectivamente, para este autor, los presos chilenos durante la época de transición posterior a los noventa, eran ejemplo de una rebeldía orientada a la transformación de la situación social en el país suramericano que hablarían de una especie de ética subversiva que el sistema social mismo rechazaría, recluyendo en la prisión a quienes eran identificados como rebeldes.

En este caso, la idea de subversión se asociaría a un grupo de movimientos rebeldes "populares radicales" que actuaban bajo la lógica de una "violencia política popular", y cuyos miembros fueron paulatinamente criminalizados y recluidos en prisión. Es decir, se trataría de un posicionamiento cercano a la idea sartreana de revolución en tanto liberación socio-antropológica (Sartre, 1971).

El análisis de este y otras situaciones de "violencia política popular" como expresión subversiva merecería un análisis aparte; sin embargo, y contrario a esas perspectivas, la tesis de la subversión como metáfora de la lógica dominante sería, en ese sentido, poco optimista respecto a 
las posibilidades reales de transformación social a partir de posiciones que se pretenden subversivas. El caso ficticio del personaje "el Jaguar" sería un buen ejemplo de ello.

Como ha señalado Nitschack (2011) la literatura ofrece un discurso donde se manifiesta lo subjetivo en dos vías: primero, en relación a los otros y, segundo, respecto a las instituciones productoras de subjetividad.

Por ello, las acciones de "el Jaguar" hablarían de una subversión que, sin embargo, lejos de romper con la lógica dominante del colegio militar Leoncio Pardo, la apuntala dentro de las relaciones de los estudiantes, generando así una especie de "rebeldía funcional" cuyo sustento en la violencia acaso logra imponer, por otras vías, el ethos imperante en el colegio.

\section{Análisis de las acciones del personaje "el Jaguar"}

De acuerdo con Nitschack (2011) la novela La ciudad y los perros, tomada como novela de formación, muestra la trayectoria del personaje "el Jaguar" como modelo de antihéroe que paulatinamente se logra adaptar a la sociedad templando un carácter apropiado. En ese sentido, la antropología propuesta por Vargas Llosa es optimista: supone una natural bondad humana que, en el más claro sentido rousseauniano, es corrompida por la sociedad.

En efecto, Vargas Llosa (1975) plantea en la novela una "totalización" según la cual, el colegio militar Leoncio Prado es una expresión de la sociedad toda, aunque con su propio espacio y tiempo

Los críticos de La ciudad y los perros han observado acertadamente que su mundo ficticio es un microcosmos de la sociedad peruana. La novela presenta una sociedad jerárquica e injusta en la que todas las relaciones sociales funcionan con base en la dominación o en la coerción (Williams, 2000, p. 6).

Como resultado del análisis realizado, se construyeron dos modelos básicos de relación que tipifican como personaje a "el Jaguar" respecto a los otros estudiantes del liceo:

1. El liderazgo basado en la violencia 


\section{La adaptación social}

El primer modelo tiene que ver con la vida dentro del colegio. El segundo con la experiencia de "el Jaguar" una vez que se ha insertado en la sociedad, ya como adulto.

\section{1. "El Jaguar" como líder dentro del Colegio Militar}

Según se puede observar en la síntesis ofrecida en el cuadro 1, las formas de relación de liderazgo violento adquieren diferentes tanto en relación con los estudiantes como con los militares.

\section{Cuadro 1.}

Acciones relativas de "el Jaguar" en el Colegio Leoncio Prado

\begin{tabular}{|l|l|l||}
\hline Modelo de relación & Acciones relativas a & \multicolumn{1}{|c|}{ Expresiones del modelo de relación } \\
\hline & $\begin{array}{l}\text { Reto: El Jaguar lo miró de arriba abajo. Se rió. - } \\
\text { Serrano cobarde -dijo- Te has orinado de miedo. } \\
\text { Mírate los pantalones (Vargas Llosa, 2007, p. 18). }\end{array}$ \\
$\begin{array}{l}\text { Agresión: } \\
\text { a) El Jaguar le incrustaba las ladillas entre los } \\
\text { pelos y yo le gritaba: "con más cuidado, } \\
\text { carambolas, me las estás metiendo por las } \\
\text { mangas". Si yo hubiera sabido que al muchacho le } \\
\text { iba a pasar lo que le ha pasado, no creo que le } \\
\text { hubiera agarrado la cabeza esa vez, ni lo habría } \\
\text { fundido tanto (Vargas Llosa, 2007, p. 227). }\end{array}$ \\
\hline $\begin{array}{l}\text { b) Y el Jaguar dijo: "oigan, tanto que quiere } \\
\text { quitarse los pelos, por qué no lo ayudamos". No } \\
\text { creo que hiciera bien, el serrano era del Círculo, }\end{array}$ \\
\hline
\end{tabular}




\begin{tabular}{|c|c|c|}
\hline Liderazgo violento & Otros estudiantes & $\begin{array}{l}\text { pero él no pierde la oportunidad de fregar. Y el } \\
\text { negro Vallano, que estaba enterito a pesar de la } \\
\text { pelea, fue el primero que se lanzó sobre el } \\
\text { serrano y después yo y cuando lo tuvimos bien } \\
\text { cogido, el Jaguar le echó la misma espuma que } \\
\text { quedaba en la brocha, le embadurnó toda la } \\
\text { frente peluda y cerca de media cabeza y comenzó } \\
\text { a afeitarlo" (Vargas Llosa, 2007, p. 257). } \\
\text { Imposición: ...nunca sería corno el Jaguar, que se } \\
\text { imponía por la violencia (Vargas Llosa, 2007, p. } \\
\text { 152). } \\
\text { Humillación: El Jaguar estaba de pie, miraba con } \\
\text { desprecio al muchacho arrodillado y todavía tenía } \\
\text { el puño en alto como si fuera a dejarlo caer de } \\
\text { nuevo sobre ese rostro lívido. Los demás no se } \\
\text { movían. "Me das asco - dijo el Jaguar- No tienes } \\
\text { dignidad ni nada. Eres un esclavo" (Vargas Llosa, } \\
\text { 2007, p. 70). } \\
\text { b) Los brazos cruzados sobre la carpeta, los ojos } \\
\text { azules clavados en el pizarrón, el Jaguar pasaba las }\end{array}$ \\
\hline
\end{tabular}




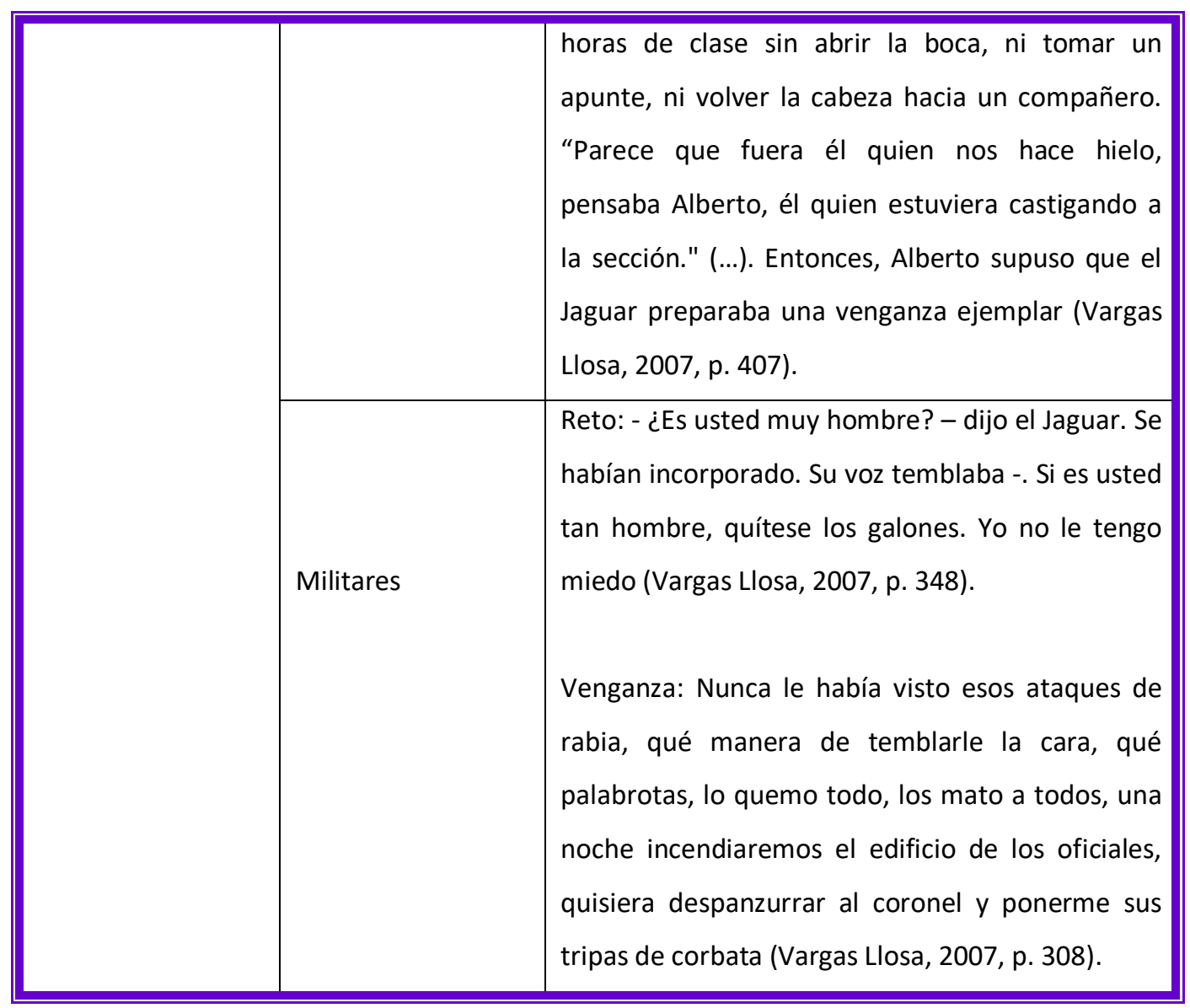

Fuente: Elaboración propia.

Si bien en la novela el personaje de "el Jaguar" aparece en primera instancia perfilado como un joven individualista, curtido en las fechorías gracias a sus andanzas previas en las calles de Lima y cuyo principio de vida radica en la salvaguarda de su propia integridad, su reconocimiento como una especie de líder corre en paralelo a la conformación del "Círculo".

Desde el primer capítulo Vargas Llosa presenta a "el Jaguar" como el principal autor intelectual o material de los ilícitos (golpizas a otros estudiantes, hurto de exámenes y de pertenencias personales, maltrato psicológico) que comete el grupo de estudiantes 
autodenominado "Círculo": grupo que nace como una forma de hermandad secreta destinada a la sobrevivencia de sus miembros.

Ahí "el Jaguar" se impone a otros induciéndolos a cometer faltas o a abusar de estudiantes vulnerables, organizando así toda una red de violencia y vejaciones que gira alrededor suyo, como una forma extrema de sobrevivencia dentro de las rígidas normas de vida dentro del colegio militar:

El Círculo comenzó a funcionar dos días más tarde, poco después del desayuno. Los tres años salían tumultuosamente del comedor y se esparcían como una mancha por el descampado. De pronto, una nube de piedras pasó sobre las cabezas descubiertas y un cadete de cuarto rodó por el suelo, chillando.

[...] El Círculo se reunía todas las noches, examinaba los diversos proyectos, el Jaguar elegía uno, lo perfeccionaba e impartía las instrucciones. (Vargas Llosa, 2007, pp. 66-67).

Así el "Círculo" nace como una forma de protección, una respuesta subrepticia y a la vez violenta a la disciplina violencia legitimada ya existente en el colegio militar. En ese sentido, el rol de "el Jaguar" aparece marcado por tres formas de relación que sustentan su liderazgo, las cuales, empero, son reflejo del tipo de relaciones institucionalizadas que observan los miliares respecto del estudiantado.

Por ejemplo, la disciplina militar impuesta en el colegio apunta a templar un carácter dispuesto a sobrevivir incluso de manera violenta a toda costa. Un diálogo entre Alberto y "el Esclavo" ilustra este punto:

- Yo no voy a ser militar.

- Yo tampoco. Pero aquí eres militar aunque no quieras. Y lo que importa en el Ejército es ser bien macho, tener unos huevos de acero, ¿comprendes? O comes o te comen, no hay más remedio. A mí no me gusta que me coman.

- No me gusta pelear - dice el Esclavo -. Mejor dicho, no sé.

- Eso no se aprende - dice Alberto -. Es una cuestión de estómago.

- El teniente Gamboa dijo eso una vez. 
- Es la pura verdad, ¿no? Yo no quiero ser militar, pero aquí uno se hace más hombre. Aprende a defenderse y a conocer la vida (Vargas Llosa, 2007, p. 30).

"El Jaguar" en diferentes episodios de la novela logra influir sobre las conductas de otros internos del colegio por medio del escarnio, cuestionando la valentía de aquel a quien desea someter a sus mandatos, tal como lo evidencian los siguientes fragmentos:

Mientras que cuestionaba a los otros, "el Jaguar" cuidaba que su presencia fuera percibida con temor y un respeto basado en su pretendida valentía y falta de escrúpulos para dañar a los demás, ya fueran estudiantes o militares a cargo del colegio.

Pero también en determinadas circunstancias "el Jaguar" evita inmiscuirse directamente en las actividades ilícitas de "el Círculo", y encomienda a los otros miembros del clan la comisión de diversas fechorías.

No se trata, pues, de un personaje cuyo ejercicio de la violencia se justifique en razón de su lucha contra la injusticia vivida en el Colegio Militar Leoncio Prado según afirma Demouche (2016), sino que su recurrente violencia sea un verdadero estilo de liderazgo que le permite afrontar la realidad vivida dentro de una institución en la que la violencia es monopolio, aparente, de los militares.

En ese sentido, "el Jaguar" es representado como una especie de maligna fuerza de la naturaleza:

Dicen que los animales se dan cuenta de las cosas por el olor; huelen y ya está, por la nariz les entra todo lo que va a ocurrir. Mi madre dice: el día del terremoto del 40 supe que iba a pasar algo, de repente los perros del barrio se volvieron locos, corrían y aullaban como si vieran al diablo con sus cachos y sus pelos de alambre. Poquito después comenzaba la tembladera. Igualito que el Jaguar. Puso una cara de ésas y dijo "alguien ha pegado un soplo", "juro por la virgen que sí", y Huarina y Morte ni habían asomado, ni se oían sus pasos, ni nada (Vargas Llosa, 2007, pp. 180-181). 
El recurso a la violencia de este personaje no puede entenderse como una rebelión contra lo vivido en el colegio militar, sino que es, en buena medida, un refinamiento de la coerción que institucionalmente se ejerce en contra de los estudiantes.

Incluso, el episodio en el que "el Jaguar" bautiza a "el Esclavo" muestra una forma descarnada y agresiva de parafraseo de la dialéctica del amo y el esclavo: Ricardo arrodillado implorando piedad a "el Jaguar" que, a partir de ese momento erige su presencia en una forma de legalidad perversa frente a los otros. A partir de ahí la única manera en que "el Esclavo" puede salir del encierro colegial, es, al mismo tiempo, saliendo del "Círculo" y delatando a Cava. Es la paradoja de encierro perpetuo a cambio del encierro actual donde la libertad de uno implica la cautividad de otro sin solución intermedia.

Ante ese episodio el crimen de "el Jaguar" parece basarse en sus valores sobre la virilidad, la lealtad y la amistad. Parece una forma de autosacrificio preferido a la ingratitud de los otros cadetes. "Yo quería vengar a la sección..." (Vargas Llosa, 2017, p. 421) y confiesa que asesina a "el Esclavo" por defensa propia y de la sección, es decir, la pervivencia propia supone el aniquilamiento del otro.

El personaje es, por lo tanto, un líder violento, una especie de legislador capaz de imponer su propia ley y, por ello, de entrar en conflicto con los representantes oficiales de la ley dentro del colegio. Su faceta de legislador arbitrario es la que lo lleva a tratar de hacer justicia ante quien haya delatado a él y los suyos:

Eres un desgraciado, Jaguar. Ahora te van a expulsar. ¿Sabes cuál va a ser tu vida? La de un delincuente, te meterán a la cárcel tarde o temprano.

-Mi madre también me decía eso. -Alberto se sorprendió, no esperaba una confidencia. Pero comprendió que el Jaguar hablaba solo; su voz era opaca, árida- Y también Gamboa. No sé qué les puede importar mi vida. Pero yo no era el único que fregaba al Esclavo. Todos se metían con él, tú también, poeta. En el colegio todos friegan a todos, el que se deja se arruina. No es mi culpa. Si a mí no me joden es porque soy más hombre. No es mi culpa. 
-Tú no eres más hombre que nadie -dijo Alberto- Eres un asesino y no te tengo miedo.

Cuando salgamos de aquí vas a ver.

-¿Quieres pelear conmigo? -dijo el Jaguar.

-Sí.

(...)-Yo te denuncié, Jaguar. Yo sé que tú lo mataste.

Esta vez Alberto no se movió. El Jaguar se había encogido en la tarima.

-¿Tú le has dicho eso a Gamboa? -dijo el Jaguar, muy despacio.

-Sí. Le dije todo lo que has hecho, todo lo que pasa en la cuadra.

-¿Por qué has hecho eso?

-Porque me dio la gana.

-Vamos a ver si eres hombre -dijo el Jaguar incorporándose (Vargas Llosa, 2007, pp. 376377).

\section{2. "El Jaguar" como individuo socialmente adaptado}

Pese a observar conductas subversivas dentro del colegio y a que incluso Alberto le augurara que tarde o temprano acabaría en la cárcel, cuando crece "el Jaguar" se ubica como un individuo socialmente funcional: se casa con Teresa (la joven que varios jóvenes colegiales amaron) y logra emplearse en una agencia bancaria. Incluso, está en condición de ofrecer ayuda a Higueras, que, contrario a él, ha terminado como un delincuente común (Ver Cuadro 2).

\section{Cuadro 2.}

Acciones relativas de "el Jaguar" en su inserción social

\begin{tabular}{|l|l|l|}
\hline Modelo de relación & Acciones relativas a & Expresiones del modelo de relación \\
\hline & & $\begin{array}{l}\text { Formación de pareja: -Es una chica simpática -dijo el flaco } \\
\text { Higueras-. Por lo que me cuentas, veo que es simpática. No } \\
\text { debiste decir eso de su tía. } \\
\end{array}$ \\
& -Ahora me llevo bien con ella -dijo el Jaguar-. Pero cuando \\
\hline
\end{tabular}




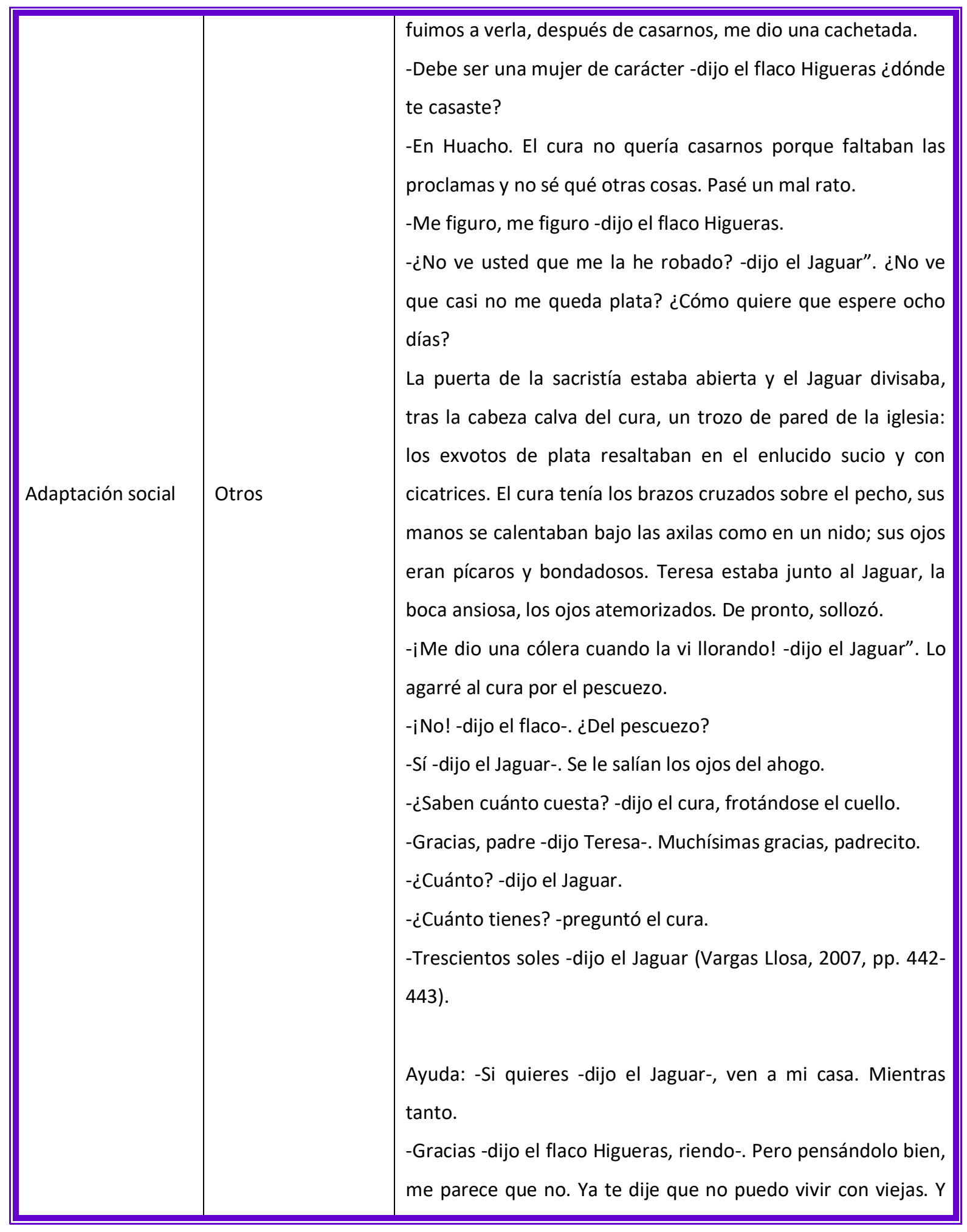




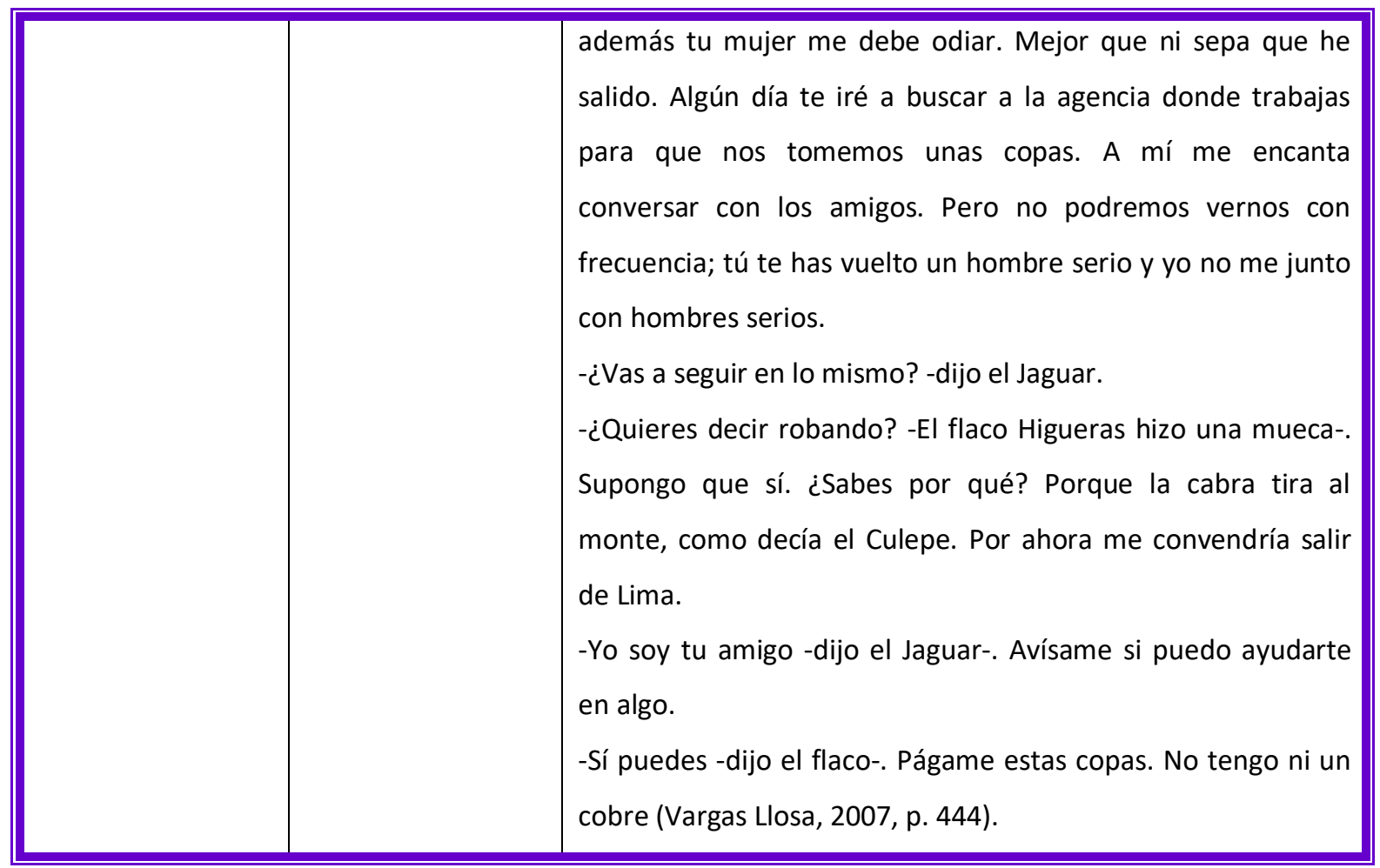

Fuente: Elaboración propia.

Se puede afirmar que "el Jaguar" crece en un sentido antropológico del término, es decir, asume un rol aparentemente funcional dentro del entramado social, dejando atrás los juveniles días de agresividad y resistencia rayana en lo criminal. En ese sentido, su final como personaje en La ciudad y los perros constituye una especie de arquetipo: juvenil antihéroe cuya evolución hacia la vida adulta lo sitúa en el lugar de una plena adaptación a la sociedad.

No obstante, "el Jaguar" sigue siendo un personaje caracterizado por encarnar cierta forma de virilidad, pero ahora, definida desde su acomodo en un rol signado por su vinculación laboral y la conformación de un hogar del que es jefe.

Así, la subversión que afianza al sistema se completa presentando al otrora arbitrario y violento estudiante, siempre dispuesto a burlar la normativa institucional del colegio en tanto versión subterránea de la disciplina militar, convertido en un ciudadano cuyo carácter finalmente se 
fraguó al calor de los rigores de una educación castrense. Incluso, su adaptación social es tal que puede ayudar a quien en su infancia y adolescencia fungiera como una especie de mentor en las fechorías de antaño.

El personaje emerge así como un símbolo de la versión sub (subversión) de una forma de armonización conductual con el discurso de la plena adaptación a la sociedad, a pesar de que la sobrevivencia en esta se base en "batir" a los otros o ser "batido" (como en un permanente duelo) por los demás.

El final de la novela y el específico destino de "el Jaguar" recuerdan cómo la socialización marca al sujeto, imbuyendo en él disposiciones que si durante la adolescencia pudieron tomar la forma de violentos comportamientos, en la edad adulta puede conciliarse con los requerimientos sociales de ámbitos como el trabajo o la familia.

\section{Discusión}

En síntesis, la hipótesis de trabajo que subyace al análisis ofrecido, propone que la expresión de una subjetividad aparentemente subversiva como la de "el Jaguar", no sería sino parte de una misma lógica social dominante que se presenta como una versión sub, una expresión quizá hasta radical, si se quiere, despojada de edulcorantes.

En efecto, al interior del colegio militar, en donde las relaciones están marcadas por la vejación y la subordinación apuntaladas por la violencia, los actos de "el Jaguar" parecen una consecuencia esperable.

Pero es interesante que Vargas Llosa al final reserve para un personaje como este una adaptación social aparentemente poco problemática. ¿Qué indicios de lo subjetivo ofrece esta "tesis" del autor?

La novela, en cuanto discurso donde se manifiesta lo subjetivo en relación a otros y respecto a las instituciones productoras de subjetividad, tal como mencionó Nitschack (2011), muestra un cuadro de sujetos capturados dentro de relaciones marcadas por la violencia física o simbólica. 
De ese modo, por una parte, el sometimiento apela, del lado de las autoridades del colegio, a lo que Foucault (2009) determinara como formas disciplinarias de los cuerpos y a la acción de cierta ortopedia del alma. Se trata, pues, de la configuración de los sujetos a partir de un régimen disciplinario perverso en el sentido de que la única posibilidad de resistirlo es la criminalidad; conducta que, mientras es castigada se legitima como única posibilidad de afirmación subjetiva.

Las acciones de "el Jaguar" plantean una subjetividad subversiva que, lejos de romper con la lógica dominante del colegio, la apuntala dentro de las relaciones y la subjetividad de los estudiantes, generando así una resistencia funcional cuyo sustento en la violencia acaso logra imponer, por otras vías, la ética del colegio mismo como sistema.

Quizá la dimensión arquetípica del personaje guarde relación con la representación de la violencia social vivida por la sociedad peruana de los sesenta. Si bien estaríamos proponiendo con esto una hipótesis sobre la homología entre la obra y la estructura social vivida por su autor, verificarla sería objeto de otro estudio. Empero, sí es posible, en este punto, entrever en la propuesta de Vargas Llosa un cierto posicionamiento sobre la violencia como forma de relación en general que se decanta por una visión moderna de la moral como problema del individuo.

Si bien Nitschack tiene razón al afirmar respecto a la novelística latinoamericana que la representación de la violencia ha estado presente por mucho tiempo, lo cual plantea el dilema de "Cómo representar la violencia sin estetizarla, es decir sin convertirla en un placer que no se corresponde con lo que se produce efectivamente" (citado por Bermúdez, 28 septiembre 2011, párr. 31), quizá en La ciudad y los perros la preocupación de Vargas Llosa, lejos de una estetización vacía de la violencia, se ubica en una consideración, sumamente moderna, de la moral individual y la capacidad del individuo como único responsable de su derrotero moral.

Williams (2000) así lo percibe en parte de la crítica literaria que prestó atención a la dimensión ética que podía seguirse de la obra de Vargas Llosa, crítica que

Por una parte, recalca el hecho de que las decisiones morales son importantes en la primera obra de Vargas Llosa, desde Los jefes hasta Conversación en la Catedral, un 
fenómeno muy estrechamente relacionado con las lecturas que el autor peruano hizo de los franceses que tanto se preocupaban por la problemática moral, desde Malraux hasta Camus y Sartre. Por otra, es interesante que un pecado ideológico, según muchos intelectuales de los años sesenta (el énfasis en la conciencia moral de un individuo, en vez de la colectividad) es la espina dorsal del programa político de Vargas Llosa dos décadas después: la política de Vargas Llosa como candidato a la presidencia del Perú recalcaba la responsabilidad del individuo por encima de la colectividad (p. 4).

La propuesta ética de Vargas Llosa en La ciudad y los perros y, particularmente en el dibujo de la subjetividad del personaje "el Jaguar", otorga especial preponderancia a la dimensión moral individual: no es el sujeto colectivo el que puede cambiar las estructuras sociales, es el individuo, en el proceso mismo de su socialización quien podrá o no insertarse provechosamente en la estructura social.

La subversión ensayada por un adolescente apodado por su aspecto físico pero también por su ferocidad como "el Jaguar", al interior del colegio, adviene en preparación para una transitoria adaptación social que, sin sobresaltos, permite al sujeto forjado por relaciones violentas constituirse en un individuo socialmente funcional, de modo tal que el personaje sería la metafórica versión subterránea de una moral dominante, que armoniza las agonías individuales con las posibilidades sociales más estereotípicas.

\section{Referencias:}

Bermúdez, M. (28 septiembre 2011). Horst Nitschack: existe un peligroso goce literario de la violencia. Suplemento Forja. Semanario Universidad. Recuperado de http://semanario.ucr.ac.cr/index.php/suplementos/forja/4577-horst-nitschack-existe-unpeligroso-goce-literario-de-la-violencia.html. 
Carrasco, E. (2012). La subversión y los movimientos definidos desde la acción política [versión electrónica]. CISMA, Revista del Centro Telúrico de Investigaciones Teóricas. (2) 1o semestre, 1-16.

Collins-Sussman, B; Fitzpatrick, B \& Pilato, M. (2004). Version Control with Subversion. Sebastopol, California: O’Reilly Media Inc.

Demouche, S. (2016). Estudio analítico y temático de la obra "La ciudad y los perros" de Mario Vargas Llosa. (Tesina para la obtención del Máster en Lengua y comunicación). Facultad de Letras y de Lenguas, Universidad de Abou Bakr Belkaid-Tlemcen, República Argelina Democrática y Popular.

Foucault, M. (2009). Vigilar y castigar: nacimiento de la prisión. Buenos Aires: Siglo XXI.

Martínez-Hoyos, F. (2015). La fábrica de machos en La ciudad y los perros [versión electrónica]. La Colmena. (85) enero-marzo, 19-29.

Medina, E. (2012). Lima: encierro y evasión en La ciudad y los perros de Mario Vargas Llosa. Ángulo Recto. Revista de estudios sobre la ciudad como espacio plural, 4(1), 5-13.

Montes, C. (2011). El imaginario perruno en La ciudad y los perros de Mario Vargas Llosa [versión electrónica]. Revista Chilena de Literatura. 80, 65-86.

Negri, A. (2006). Fábricas del sujeto / Ontología de la subversión. Madrid: Akal.

Nitschack, H. (2011). Ciudadanía y subjetividad en la novela urbana latinoamericana. Curso corto dictado en el Doctorado en Estudios de la Sociedad y la Cultura, 14-23 de setiembre. San José: Universidad de Costa Rica.

Pérez, F. (2001). Investigar la ética de la subversión lingüística. Pequeña teoría sobre diccionarios, purismo y subversión [versión electrónica]. Cifra nueva. (13), enero-junio, 127-133.

Real Academia de la Lengua Española. (2001). Subvertir. Diccionario de la lengua española. Recuperado de http://buscon.rae.es/drael/.

Rosas, P. (2004). Rebeldía, subversión y prisión política. Crimen y castigo en la transición chilena 1990-2004. Santiago de Chile: Lom. 
Salazar, B. (2005). La Violencia como temática en La Ciudad y los Perros de Mario Vargas Llosa. (Seminario de licenciatura), Departamento de Literatura, Facultad de Filosofía y Humanidades, Universidad de Chile.

Sartre, J. (1971). Materialismo y revolución. Buenos Aires: Pléyade.

Ulloa, G. (2006). Identidad religiosa en el contexto institucional católico costarricense. Aportes para una aproximación psicocultural al lenguaje religioso de la identidad. Tesis de posgrado presentada ante el Programa de Maestría en Estudios de Cultura Centroamericana, Facultad de Filosofía y Letras, Universidad Nacional.

. (2007). Hipótesis sobre la subversión religiosa en el Rastafarismo [versión electrónica]. Reflexiones. 86(1), 115-126.

Vargas, M. (2007). La ciudad y los perros. México: Punto de lectura.

Williams, R. (2000). Los primeros demonios. La ciudad y los perros. Los universitarios. (2) nueva época, 4-7 